\title{
Influence of tribological test on the global conversion of natural composites
}

\author{
Carlos Eduardo Correa ${ }^{1}$, Robin Zuluaga ${ }^{2}$, Cristina Castro $^{3}$, Santiago Betancourt ${ }^{4}$, \\ Analía Vázquez ${ }^{5}$ and Piedad Gañán ${ }^{6 *}$
}
${ }^{1}$ Grupo de Nuevos Materiales, Universidad Pontificia Bolivariana - UFB, Medellín, Antioquia, Colombia
${ }^{2}$ Facultad de Ingeniería Agroindustrial, Universidad Pontificia Bolivariana - UFB, Medellín, Antioquia, Colombia

${ }^{3}$ Facultad de Ingeniería Textil, Universidad Pontificia Bolivariana - UFB, Medellín, Antioquia, Colombia

${ }^{4}$ Facultad de Ingeniería Mecánica, Universidad Pontificia Bolivariana -

UFB, Medellín, Antioquia, Colombia

${ }^{5}$ Consejo Nacional de Investigaciones Científicas y Técnicas - CONICET, Instituto de Tecnología en Polímeros y Nanotecnología, Universidad de Buenos Aires UBA, Buenos Aires, Capital Federal, Argentina

${ }^{6}$ Facultad de Ingeniería Química, Universidad Pontificia Bolivariana - UFB, Medellín, Antioquia, Colombia

*piedad.ganan@upb.edu.co

\begin{abstract}
The vinyl ester resins and natural composites have emerged as a suitable alternative in tribological application due to mechanical behavior, which relates to the conversion of the double bonds. During tribological test the permanent contact between polymeric sample and counterpart can increase the temperature affecting the crosslinking of the samples. These variations have direct implications in the curing rate and the global conversion. In this work, the FTIR evaluation is used to evaluate possible changes on the global conversion of vinyl ester and their composites reinforced with Musaceae fiber bundles and cured using two hardeners, after a specific tribological test. Increments around $15 \%$ on global conversion of styrene double bonds were observed for neat matrix and composites using both hardeners, suggesting that during tribology test some alterations on resin structure takes place. These results open alternatives to manipulate the curing conditions in order to control the tribological behavior.
\end{abstract}

Keywords: FTIR analysis, global conversion, natural fiber composites, tribology test, vinyl ester matrix.

\section{Introduction}

Polymers such as unsaturated polyester resins, epoxy resins and vinyl ester resins have been used as matrix for composite materials in an uncountable amount of technical applications ${ }^{[1-11]}$. The most popular of them due to the low cost, reasonable good properties and simplicity for processing are the unsaturated polyester resins, but when better mechanical or chemical resistance properties are required, the epoxy resins are preferred. However, they are commonly used in applications where the cost is not essentially a problem. The vinyl ester resin, being a mixture of the previously mentioned resins combines the easy processing and curing of the unsaturated polyester resins with the high mechanical, thermal and chemical properties of the epoxy resins ${ }^{[9,11-13]}$.

The vinyl ester resins are a kind of unsaturated polyester resins that have chain terminations of an acrylate or methacrylate groups. They are family with the common unsaturated polyester resins, but they usually are diesters that contain ether linkages and vinyl functional groups ${ }^{[8,14]}$. The main structure may come from several other common resins such as epoxy, urethane or many more, but the most common are the epoxy resins.

The resins with an epoxy backbone are commonly a copolymer of ethylenically unsaturated carboxylic acids like acrilyc or methacrilyc acid ${ }^{[8,15-18]}$ and components of the epoxy resins, for example the diglycidyl eter of bisphenol A (DGEBA). These resins may be used neat ${ }^{[15,19,20]}$, however, they are usually diluted in a vinyl-type reactive co-monomer, most commonly used is the styrene monomer ${ }^{[8,14,15,19,21]}$. The reaction may be catalyzed by ammonium salts, ternary amines, alkalis or phosphines and it takes place at moderately elevated temperatures ${ }^{[8,10]}$, temperatures between 60 to $120^{\circ} \mathrm{C}$.

Curing of vinyl ester resins is potential by $\mathrm{C}=\mathrm{C}$ double bond located at the ends of the chains. Due to this fewer $\mathrm{C}=\mathrm{C}$ bonds these resins have a lower crosslinking density compared with the unsaturated polyester resins, and as these bonds are in the extremes of the chain, they are easier to be accessed, which may lead to an almost complete conversion in the curing ${ }^{[8,22]}$.

The vinyl ester resins can be possibly used in less common applications as tribological evaluation, when it is always recommended that matrix experiment the less modification possible as weight loss. The potential of vinyl ester resins and their composite use in tribology are increasing, some works in this field include composites reinforced with 
glass reinforcements ${ }^{[23,24]}, \mathrm{SiC}$ filler ${ }^{[23]}$, carbon fabric ${ }^{[24]}$, or natural fibers ${ }^{[25,26]}$.

During the tribological test increments on temperature due to the contact with counterpart, traditionally metallic, are possible. These phenomena could affect the crosskling of vinyl ester samples. However, there are no studied about the effect of this test on the resin structure during or after this takes place, in spite the importance of the plastic behavior of the tribological systems.

This potential affection is based on that the curing process is a heterogeneous, highly exothermic free radical copolymerization $^{[15,22]}$ where three reactions occur at the same time: vinyl ester homo-polymerization, styrene (or any other unsaturated vinyl monomer as mentioned before) homo-polymerization and vinyl ester-styrene copolymerization $^{[3,8,13,17]}$. The crosslinking reaction undergoes in differential form because the vinyl ester double bonds at the beginning of the reaction, reacts faster than the ones of the styrene, but in the final part is the opposite. This differential in the crosslinking forms microgels which grows and coagulate and then adding between them, which brings to the final nodular form ${ }^{[5,13,22,27]}$. The reaction rate of the vinyl ester and the monomer may be divided in two parts, a faster one, where the maximum rate of reaction is located may be due to the easier diffusion of the components. However at higher conversions a three dimensional gel structure appears and the diffusion of the long chain radicals is more difficult to occur and the reaction slows down ${ }^{[6]}$, and potential alterations on temperature of the sample could affect this last conversion.

In order for curing process to take place, peroxides or hydroperoxides are used as initiators, and are also known as hardeners. At high temperature curing these hardeners may be used alone or at room temperature curing is required the use of a redox initiation system ${ }^{[3]}$ of promoter (initiator, hardener) and activator (accelerator), these are systems of the peroxide, cobalt salts and/or ternary amines ${ }^{[28]}$, not always with the three components. The vinyl ester resins may also be cured via photo-polymerization ${ }^{[8]}$ using an appropriate photoinitiator ${ }^{[21]}$. Radiations used to the photo-curing of the resins are ultraviolet ${ }^{[14,29]}$, visible light ${ }^{[7]}$ and electron beam $^{[14,30]}$.

For the curing of the vinyl ester the hardeners used are methyl ethyl ketone peroxide (Mek peroxide) which is the most common for room temperature curing ${ }^{[6,20,29,31]}$. Also are used diacylperoxides, peresteres, diaryl peroxides, dialkyl peroxides, hydroperoxydes such as cumene hydroperoxyde ${ }^{[3]}$ cumyl hydroperoxyde ${ }^{[5]}$, for high temperature curing the

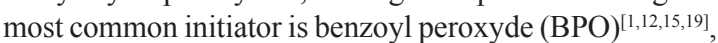
but t-butyl proxy-benzoate ${ }^{[22]}$ is used as well sometimes. An activator does the decomposition in free radicals of the initiators. This activation may be done using chemicals, temperature or radiation. On the other hand, as secondary promoters a ternary amine is used to complement the action of the accelerator, or just used to accelerate when the hardener is BPO. When the resin cures, there are several things that may affect the curing of the resin such as the temperature and time, the diluent reactive monomer, the amount of hardener, accelerator and inhibition products.
When the styrene content is changed in part or completely with $\alpha$-methyl styrene the viscosity, gel time and peak curing temperature have the same behavior as the one mentioned with only styrene when the fraction of the $\alpha$-methyl styrene is increased in the formulation of the resin ${ }^{[1,19]}$. The variation of the components of the initiation system, cobalt salt and peroxide, also affects the crosslinking reaction kinetics. When the isothermal curing temperature is increased the reaction rates and overall conversion of the resin increases ${ }^{[32]}$. However the final conversion of the resin has a maximum at intermediate temperatures where it reaches almost complete curing, but at higher temperatures than those mentioned the final conversion does not reach that value ${ }^{[6]}$.

The global or final conversion degree of the cure after a post-curing process in the vinyl ester resin is independent of the isothermal curing temperature in the material[33]. The postcure of the resins may also be done via radiation like microwaves ${ }^{[1]]}$. However, no mention or studies of variations of global or final conversion of the resin after a test, such as tribological test, have been found.

On the other hand, the curing and poscuring evolution of vinyl ester resins have been studied using different types of techniques such as thermal analysis DSC test, DMA test, FTIR spectroscopy or RAMAN spectroscopy ${ }^{[34]}$. FTIR spectroscopy and its variations such Attenuated total reflection (ATR) could be an interesting technique of analysis to obtain the curing process and to obtain the initial information about the potential alteration of resin structure due to modifications or alterations of conversion during applications or test.

As mention before, the vinyl ester is a very versatile system, and it is possible to manipulate is global conversion by variation on temperature such the case of the tribological applications. In this study, the potential use of ATR-FTIR spectroscopy to monitor the potential variations of conversion of vinyl ester during a tribological test is analyzed, and interesting variations on global conversion of matrix have been observed. Additionally to neat matrix, natural composites reinforced with natural fibers such as Musaceae fiber bundles are considered. The use of this type of fiber bundles is due to the interesting qualities of their composites for the tribological applications, that have been evaluated in previous work ${ }^{[25,35]}$.

\section{Materials and Methods}

\subsection{Materials}

In this analysis a vinyl ester resin, reference Swancor 901-3 kindly supplied by Andercol S.A. was used. Two hardeners, methyl-ethyl-ketone peroxide (Mek) and benzoyl peroxide (BPO) were used.

The fiber bundles used in this work were extracted from the rachis of Colombian Musaceae plants, and were kindly supplied by Banacol S.A. Fiber length used in this work corresponds to $287 \mu \mathrm{m}$.

\subsection{Composite fabrication}

Composite samples were prepared using a BMC fabrication technique. Resin, hardener and fiber bundles were mechanically mixed, then the mix was put in a mold and compressed at $1000 \mathrm{psi}$. The curing condition corresponds to 
$100{ }^{\circ} \mathrm{C}$ during $1 \mathrm{~h}$, these conditions were defined according with previous work ${ }^{[35]}$. This condition was chosen in order to explore potential variations of curing conversion of vinyl ester resin after the tribological test. All composites samples contained a $10 \mathrm{wt} \%$ of fiber bundles, whereas as the amount of hardener corresponds to $1.5 \mathrm{wt} \%$. Figure 1 summarizes the fabrication process. The void content of neat and composites samples were less than $1 \%$. Additionally, non-debonding problems were registered in samples after fabrication process.

\subsection{Tribological test}

Five samples with $9 \mathrm{~mm}$ in diameter were cut and attached to a $10 \mathrm{~mm}$ long metallic pin with cyanoacrylate contact adhesive. Pins were machined to reach a diameter of $6.3 \mathrm{~mm}$. The tribological test was performed using a pin on disc machine as the one schematized elsewhere ${ }^{[35]}$. According to this previous study, the most adequate parameters of the experiment test corresponds ${ }^{[35]}: 200 \mathrm{~m} \mathrm{~min}^{-1}$ of speed, recorded distance corresponds to $3 \mathrm{~km}$, and normal load to $4.9 \mathrm{~N}$. The counter body used was a 1040 steel, a common material for the evaluation of the tribological behavior of polymers. Figure 2 shows a pin on disc machine.

\subsection{Infrarred spectroscopy}

Attenuated total reflection Fourier transform infrared spectroscopy (ATR-FTIR) Nicolet 6700 supplied by Thermo Scientific was used for FTIR analysis. The FTIR spectra were recorded on a Nicolet 6700 spectrophotometer in the $4000-400 \mathrm{~cm}^{-1}$ range using ATR. The spectra were recorded with a resolution of $4 \mathrm{~cm}^{-1}$ and an accumulation of 64 scans. Evaluations were developed on cured samples before and after the tribological test.

To evaluate the final or global conversion of vinyl ester double bonds $\left(\mathrm{a}_{\mathrm{VE}}\right)$ and global conversion of styrene double bonds $\left(\mathrm{a}_{\mathrm{S}}\right)$ before and after tribological test, in order to evaluate potential alterations on curing, Equations 1 and 2 are used. These equations are adapted from Ziaee and Palmese work ${ }^{[5]}$.

$$
a_{V E}=1-\left(A B S_{F} 945 \mathrm{~cm}^{-1} / A B S_{0} 945 \mathrm{~cm}^{-1}\right) \times\left(A B S_{0} 830 \mathrm{~cm}^{-1} / A B S_{F} 830 \mathrm{~cm}^{-1}\right)(1)
$$$$
a_{S}=1-\left(A B S_{F} 910 \mathrm{~cm}^{-1} / A B S_{0} 910 \mathrm{~cm}^{-1}\right) \times\left(A B S_{0} 710 \mathrm{~cm}^{-1} / A B S_{F} 710 \mathrm{~cm}^{-1}\right)
$$

\section{5 $\mathrm{ABS}_{0}$ represents the peak height of uncured matrix}

$\mathrm{ABS}_{\mathrm{F}}$ represents the peak height at end process, which corresponds after curing process or after tribologial test.

Vibration at $945 \mathrm{~cm}^{-1}$ corresponds to out of plane bending of C-H double bond of vinyl groups, and $910 \mathrm{~cm}^{-1}$ corresponds to double bonds of styrene monomer. To evaluate the global conversion is required vibration not affected by curing process. In this case corresponds to aromatic groups of vinyl ester located at $830 \mathrm{~cm}^{-1}$ and $700 \mathrm{~cm}^{-1}$ for styrene monomer. Table 1 summarizes the sample convention analyzed in this work.

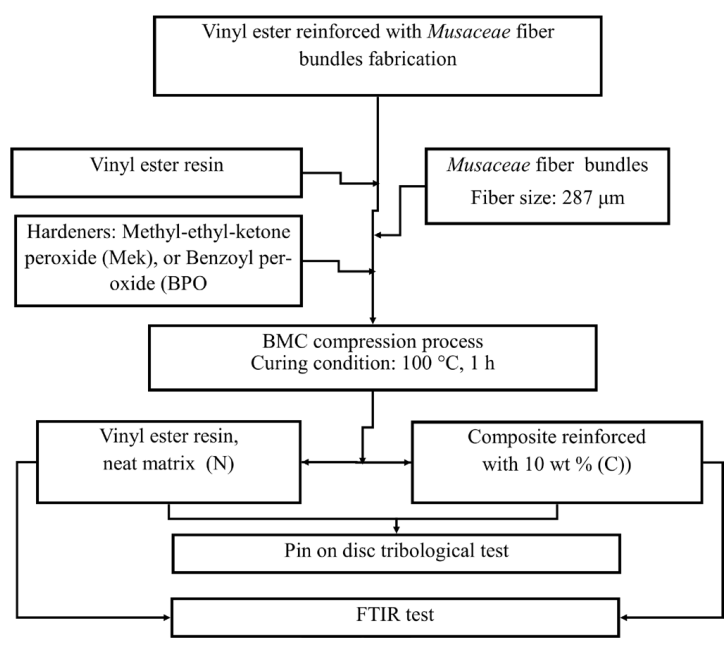

Figure 1. Scheme of vinyl ester resin and composites fabrication and evaluation.

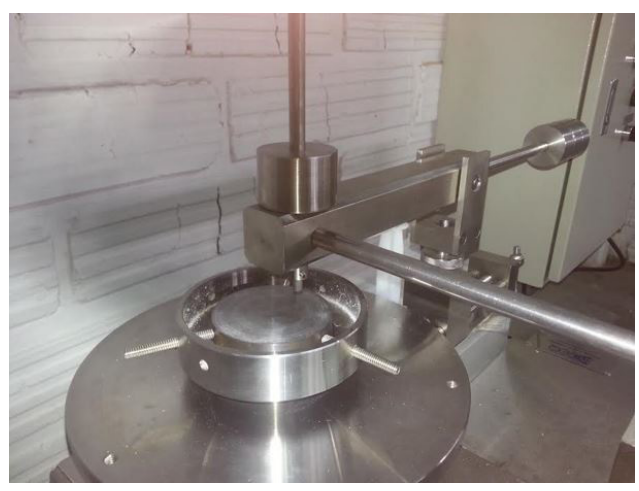

Figure 2. Pin on disc machine.

Table 1. Convention of analyzed samples.

\begin{tabular}{lcc}
\hline \multicolumn{1}{c}{ Type of material } & Curing agent & Abbreviation \\
\hline Neat matrix before tribological test & Mek peroxide & NMBT-Mek \\
Neat matrix after tribological test & Mek peroxide & NMAT-Mek \\
Neat matrix before tribological test & BPO & NMBT-BPO \\
Neat matrix after tribological test & BPO & NMAT-BPO \\
Composite before tribological test & Mek peroxide & CBT-Mek \\
Composite after tribological test & Mek peroxide & CAT-Mek \\
Composite before tribological test & BPO & CBT-BPO \\
Composite after tribological test & BPO & CAT-BPO \\
\hline
\end{tabular}

\section{Results and Discussions}

As Figure 3 shows, uncured vinyl ester resin spectra, characteristic vibration of vinyl ester resin corresponds to ester linkage due to formed carbonyl group through the transformation of epoxy group are observed at $1715 \mathrm{~cm}^{-1[36]}$. A broad vibration between 3628 and $3142 \mathrm{~cm}^{-1}$ is associated with hydroxyl groups; centered peak corresponds to $3445 \mathrm{~cm}^{-1}$. In areas around 1630,945 or $830 \mathrm{~cm}^{-1}$ present vibrations correspond to $\mathrm{C}=\mathrm{C}$ vibration of methacylate and styrene monomer, the main groups responsible of curing process of this resin. These vibrations can be overlapped. Characteristic vibration of aromatic ring are observed at 1607 and $1508 \mathrm{~cm}^{-1[34]}$. 
Table 2 summarizes the main vibrations of the uncured vinyl ester resin dissolved in styrene.

FTIR technique helps to evaluate global conversion of monomers or reactive groups that participate during curing reaction, such as the case of styrene and vinyl ester double bonds ${ }^{[5]}$. In this case, global conversion before and after tribological test of these groups are evaluated for both neat and Musaceae fiber bundles composites. These composites were evaluated due to the potential importance for tribological

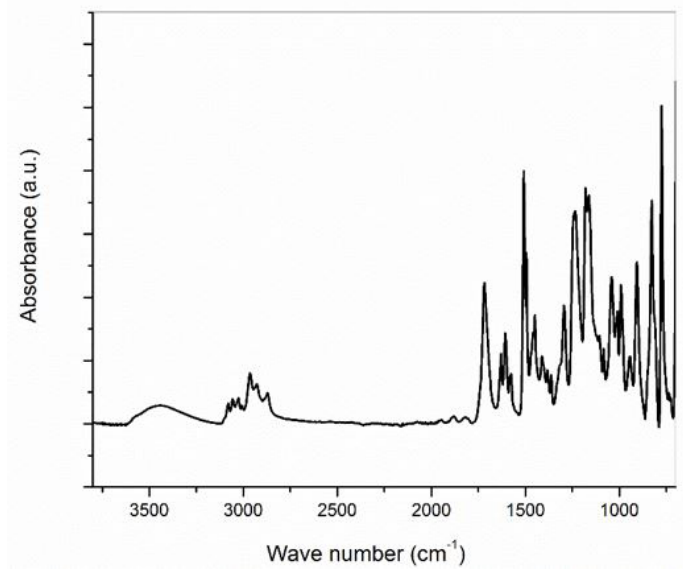

Figure 3. Uncured vinyl ester resin. applications ${ }^{[25]}$. Figures 4 to 6 show the final conversion of final or global conversion of vinyl ester double bonds and global conversion of styrene double bonds before and after tribological test when two different types of hardeners are used. According with Figure 4, increments on global conversion of vinyl ester groups of neat resin samples are observed after tribological test. These modifications are most significant when the Mek-peroxide is used as hardener. For styrene groups, the variations on global conversion of neat resin samples are registered in Figure 5. In this case, when BPO peroxide is used, the alterations are of the most significant. When composite samples are analyzed, see Figure 6, the global conversion of styrene double bonds groups before the tribological test is lower than neat resin, because composite samples presente at increments on the global conversion respect of the neat matrix. This behavior suggests that the presence of fiber bundles could affect the development of curing. Some authors ${ }^{[39,40]}$ have commented alteration on curing evolution of thermosetting composites systems, even when natural fibers are used as reinforcement. Musaceae fiber bundles could introduces the variations on the interfacial interactions respect to the matrix and introduce a catalytic effect on curing process and polymer chain network formation ${ }^{[41,42]}$. This phenomenon could introduce topological restrictions that reduce the impact of the evolution of the global convertion of the double bonds still present on composite samples after tribological test. Respect to the influence of tribological test on global conversion, a comparable behavior of neat resin (see Figure 5) is observed.

Table 2. Main vibrations of uncured vinyl ester resin.

\begin{tabular}{|c|c|c|}
\hline $\begin{array}{c}\text { Vibration } \\
\left(\mathrm{cm}^{-1}\right)\end{array}$ & Structure & References \\
\hline $3626-3152$ & $\mathrm{OH}$ groups of methacrylate groups. Broad region & [33] \\
\hline 3079 & $\mathrm{C}-\mathrm{H}$ aromatic ring & [27] \\
\hline 3005 & $\mathrm{C}-\mathrm{H}$ stretching vibration of alkene & [9] \\
\hline 2924 & $-\mathrm{CH}_{2}$ and $-\mathrm{CH}_{3}$ groups & [27] \\
\hline 2870 & $-\mathrm{CH}_{2}$ and $-\mathrm{CH}_{3}$ groups & [27] \\
\hline 2851 & $-\mathrm{CH}_{2}$ and $-\mathrm{CH}_{3}$ groups & [27] \\
\hline 1715 & Ester vibration & [36] \\
\hline 1636 & Shoulder associated with $\mathrm{C}=\mathrm{C}$ bonds styrene & [30] \\
\hline 1633 & $\mathrm{C}=\mathrm{C}$ bonds of methacrylate group & {$[30]$} \\
\hline 1609 & Acryl double bond $(-\mathrm{C}=\mathrm{C}-)$ & [36] \\
\hline 1607 & Stretching of $\mathrm{C}=\mathrm{C}$ present in aromatic ring & [37] \\
\hline 1581 & $\mathrm{C}=\mathrm{C}$ stretching of the aromatic ring & [27] \\
\hline 1508 & Stretching of $\mathrm{C}=\mathrm{C}$ present in aromatic ring & [37] \\
\hline 1297 & $\mathrm{C}-\mathrm{O}$ and $\mathrm{C}-\mathrm{C}$ stretching & [37] \\
\hline 1264 & Asymmetric vibrations of the $\mathrm{C}-\mathrm{O}-\mathrm{C}$ linkage and to the $\mathrm{C}-\mathrm{OH}$ vibration & [36] \\
\hline 1244 & Related with aromatic ring and $\mathrm{C}-\mathrm{O}$ interaction & [37] \\
\hline 1180 & Aromatic ring in plane and $\mathrm{C}-\mathrm{O}$ interaction & [37] \\
\hline 1041 & Aromatic ring in plane and $\mathrm{C}-\mathrm{O}$ interaction & [37] \\
\hline 1012 & Aromatic ring in plane & [37] \\
\hline 945 & $\begin{array}{l}\text { Out-of-plane bending of vinyl ester monomer. } \\
\mathrm{C}=\mathrm{C} \text { vibration of methacrylate }\end{array}$ & {$[9,37]$} \\
\hline 907 & $\begin{array}{l}\mathrm{C}=\mathrm{C} \text { vibration presents in aromatic ring. } \\
\mathrm{C}=\mathrm{C} \text { in styrene }\end{array}$ & [30] \\
\hline 830 & Out of the plane vibration of $\mathrm{C}=\mathrm{C}$ in aromatic group & {$[36,37]$} \\
\hline 696 & $\begin{array}{l}\text { Out-of-plane bending of the } \mathrm{CH} \text { groups in the aromatic ring, all the } 5 \text { hydrogen carbons oscillating in } \\
\text { phase. Typical for monosubstituited aromatic ring }\end{array}$ & [38] \\
\hline
\end{tabular}




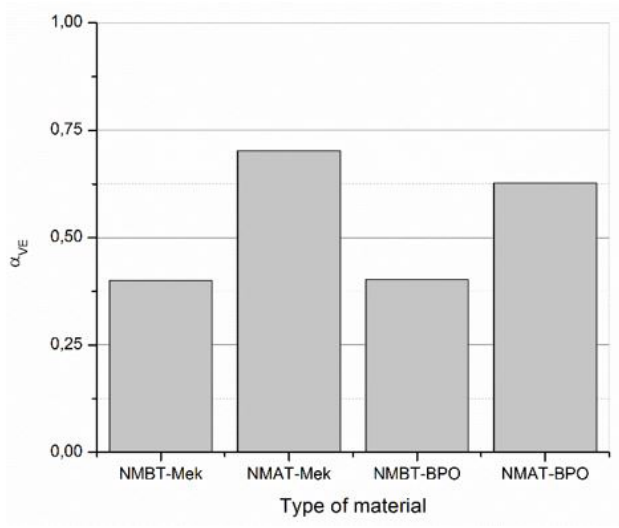

Figure 4. Global conversion of vinyl ester bonds of neat matrix samples before and after tribological test.

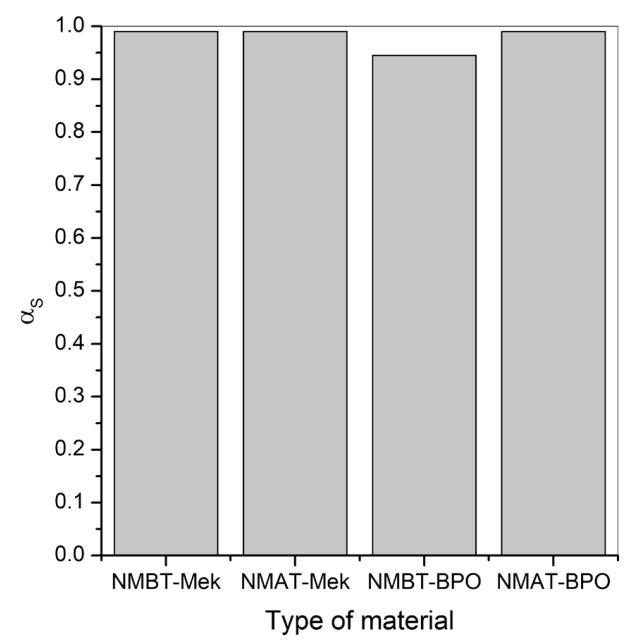

Figure 5. Global conversion of styrene double bonds of neat matrix samples before and after tribological test.

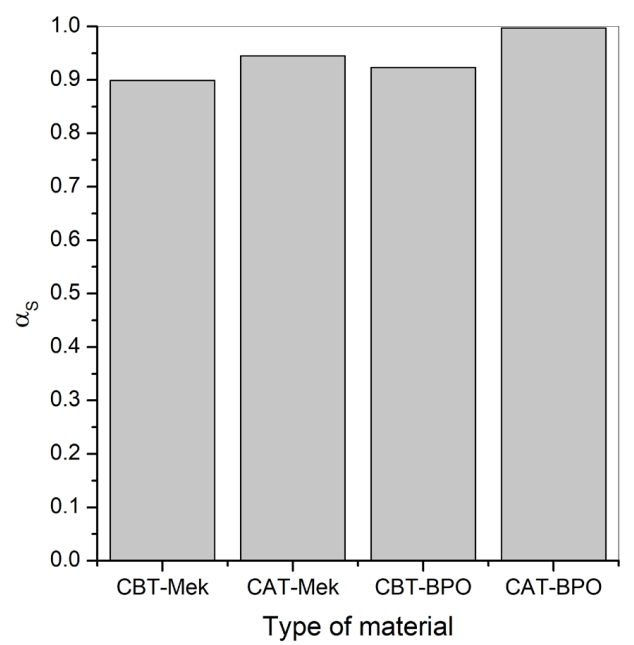

Figure 6. Global conversion of styrene double bonds of natural composite samples before and after tribological test.
After the tribological test increments on global conversion are registered, essentially when BPO peroxide is used.

The main alterations are observed in S double bonds than in VE double bonds. This behavior has been observed by authors as Brill and Palmese $\mathrm{e}^{[13]}$, and potential explanation for that, is apparently that the VE reaction starts before the styrene one. However, the reaction of styrene continues after the VE one concludes. Additionally, these authors mentioned the formation of microgel or nanogel of VE that suggest the presence of multiple phases at the molecular level during the cure process. The results obtained in this work suggest that the tribological test affects this molecular distribution and potentially affects the mechanical or physical behavior ${ }^{[5]}$. The formation of these microgels are documented by other author such as Dua et al. ${ }^{[43]}$ and Rodriguez et al. ${ }^{[27]}$ when studied the curing of these resins at different isothermal curing. However, the results presented in this work are the first to document alterations of curing after a tribological test.

These results suggest that is necessary evaluate the curing alteration that occur in vinyl ester resins when are used for this type of applications, because the slight alteration could be manipulated to improve their behavior. The variations observed when samples are cured using BPO-peroxide respect to Mek-peroxide have relation with crosslinking evolution, and as well commented for other authors when analyze mechanical or thermal behavior ${ }^{[44]}$.

These results are relevant considering that during tribological test potential plastification of the samples could affect the behavior of samples. If it is possible to control the evolution of the conversion of samples, important variations on tribological behavior could be obtained and unlimited potential applications could be developed even for neat matrix as well their natural composites because the alterations on the global convertion affects the plastic deformation of the systems, and it is reflected on the formation of film on the counterface of the counter part alterating the friction behavior. These results could be useful for sliding applications or solid lubrications requirements at dry friction conditions.

\section{Conclusions}

In this work, variations on the global curing conversion of vinyl ester resin and their natural composites before and after tribological test are analyzed using ATR-FTIR spectroscopy. According with obtained results, increments around $15 \%$ on global conversion of styrene double bonds are easier to follow using this technique. Increments superior to $30 \%$ were observed when BPO-peroxide is used as hardener, whereas the global conversion of vinyl ester double bond groups experiment more alteration when Mek-peroxide is used. The results suggest that ATR-FTIR spectroscopy could be an easier technique to use in order to monitor changes during important type of test such as tribological. However, the most important results of this work represent the relationship that exists between global conversion of double bond groups present in vinyl ester sample and tribological evaluations, according with it, is possible to manipulate the curing conditions in order to obtain different resin or matrix structure and the respective behavior during this mechanical test. These results are 
relevant considering that during tribological test a potential plastification of the samples could affect the behavior of samples. The alterations on the global convertion affects the plastic deformation of the systems and surface wear mechanisms. It can be reflected on the formation of film and transfer layer attached into the surface of the counterbody, both modifying friction behavior of tribosystem. In addition, if it is possible to control the evolution of the conversion of samples, important variations on tribological behavior could be obtained and unlimited potential applications could be developed even for neat matrix as well their natural composites, for instance, mechanical components in sliding conditions as gears or sliding dry pads in braking systems.

\section{Acknowledgements}

The authors would like to thank CIDI and Colciencias for support and funding to develop this work. Also, thanks to Andercol S.A., and Banacol for providing materials used in this work.

\section{References}

1. Siva, P., Varma, I. K., Patel, D. M., \& Sinha, T. J. M. (1994). Effect of structure on properties of vinyl ester resins. Bulletin of Materials Science, 17(6), 1095-1101. http://dx.doi.org/10.1007/ BF02757587.

2. Nawab, Y., Casari, P., Boyard, N., \& Jacquemin, F. (2013). Characterization of the cure shrinkage, reaction kinetics, bulk modulus and thermal conductivity of thermoset resin from a single experiment. Journal of Materials Science, 48(6), 23942403. http://dx.doi.org/10.1007/s10853-012-7026-6.

3. Li, L., \& Lee, L. J. (2001). Effects of inhibitors and retarders on low temperature free radical crosslinking polymerization between styrene and vinyl ester resin. Polymer Engineering and Science, 41(1), 53-65. http://dx.doi.org/10.1002/pen.10708.

4. Mouritz, A. P., Feih, S., Mathys, Z., \& Gibson, A. G. (2011). Mechanical property degradation of naval composite materials. Fire Technology, 47(4), 913-939. http://dx.doi.org/10.1007/ s10694-009-0125-5.

5. Ziaee, S., \& Palmese, G. (1999). Effects of temperature on cure kinetics and mechanical properties of vinyl-ester resins. Journal of Polymer Science. Part B, Polymer Physics, 37(7), 725-744. http://dx.doi.org/10.1002/(SICI)10990488(19990401)37:7<725::AID-POLB23>3.0.CO;2-E.

6. Cook, W. D., Simon, G. P., Burchill, P. J., Lau, M. T., \& Fitch, J. (1997). Curing kinetics and thermal properties of vinyl ester resins. Journal of Applied Polymer Science, 64(4), 769-781. http:// dx.doi.org/10.1002/(SICI)1097-4628(19970425)64:4<769::AIDAPP16>3.0.CO;2-P

7. Mao, Q., Bian, L., \& Huang, M. (2011). Study of the visible light curing of vinyl ester resins using in situ raman spectroscopy. Journal of Polymer Research, 18(6), 1751-1756. http://dx.doi. org/10.1007/s10965-011-9581-y.

8. Kandelbauer, A., Tondi, G., Zaske, O. C., \& Goodman, S. H. (1999). Unsaturated polyesters and vinyl esters. In D. Hanna, \& S. H. Goodma (Eds.), Handbook of thermoset plastics (3rd ed., pp. 111-172). San Diego: Elsevier.

9. Sultania, M., Rai, J. S. P., \& Srivastava, D. (2010). Studies on the synthesis and curing of epoxidized novolac vinyl ester resin from renewable resource material. European Polymer Journal, 46(10), 2019-2032. http://dx.doi.org/10.1016/j. eurpolymj.2010.07.014.

10. Nazareth da Silva, A. L., Teixeira, S. C. S., Widal, A. C. C., \& Coutinho, F. M. B. (2001). Mechanical properties of polymer composites based on commercial epoxy vinyl ester resin and glass fiber. Polymer Testing, 20(8), 895-899. http://dx.doi. org/10.1016/S0142-9418(01)00018-6.

11. Ku, H., Prajapati, M., \& Cardona, F. (2011). Thermal properties of sawdust reinforced vinyl ester composites post-cured in microwaves: A pilot study. Composites. Part B, Engineering, 42(4), 898-906. http://dx.doi.org/10.1016/j.compositesb.2011.01.008.

12. Scott, T. F., Cook, W. D., \& Forsythe, J. S. (2002). Kinetics and network structure of thermally cured vinyl ester resins. European Polymer Journal, 38(4), 705-716. http://dx.doi. org/10.1016/S0014-3057(01)00244-0.

13. Brill, R. P., \& Palmese, G. R. (2000). An investigation of vinyl - ester -styrene bulk copolymerization cure kinetics. using fourier transform infrared Spectroscopy. Journal of Applied Polymer Science, 76(10), 1572-1582. http://dx.doi. org/10.1002/(SICI)1097-4628(20000606)76:10<1572::AIDAPP12>3.0.CO;2-C.

14. Launikitis, M. B. (1982). Vinyl ester resins. In G. Lubin (Eds.), Handbook of composites (pp. 38-49). New York: Van Nostrand Reinhold Company Inc.

15. Gaur, B., \& Rai, J. S. P. (1992). Curing and decomposition behaviour of vinyl ester resins. Polymer Report, 33(1), 42104214. http://dx.doi.org/10.1016/0032-3861(92)90631-6.

16. Han, C. D., \& Lem, K. W. (1984). Chemorheology of thermosetting resins. IV. The chemorheology and curing kinetics of vinyl ester resin. Journal of Applied Polymer Science, 29(5), 18791902. http://dx.doi.org/10.1002/app.1984.070290538.

17. Ittner Mazali, C. A., \& Felisberti, M. I. (2009). Vinyl ester resin modified with silicone-based additives: III. Curing kinetics. European Polymer Journal, 45(8), 2222-2233. http://dx.doi. org/10.1016/j.eurpolymj.2009.05.022.

18. Rao, B. S., Madec, P. J., \& Marechal, E. (1986). Synthesis of vinyl ester resins. Evidence of secondary reactions by $13 \mathrm{C}$ NMR. Polymer Bulletin, 16(2-3), 153-157. http://dx.doi. org/10.1007/BF00955485.

19. Bhatnagar, R., \& Varma, I. K. (1989). Effect of 0t-methylstryrene of the curing behaviour of vinyl ester resins. Journal of Thermal Analysis and Calorimetry, 35(4), 1241-1249. http://dx.doi. org/10.1007/BF01913044.

20. Choudhary, M. S., \& Varma, I. K. (1993). Vinyl ester resins, 3a. Effect of ethyl methacrylate on thermal and mechanical properties. Die Angewandte Makromolekulare Chemie, 209(1), 33-39. http://dx.doi.org/10.1002/apmc.1993.052090104.

21. Penczek, P., Czub, P., \& Pielichowski, J. (2005). Unsaturated polyester resins: chemistry and technology. In A. Abe, K. Dusvek, \& S. Kobayashi (Eds.), Crosslinking in materials science (pp. 1-95). Berlin: Springer Berlin Heidelberg.

22. Li, P., Yang, X., Yu, Y., \& Yu, D. (2004). Cure kinetics, microheterogeneity, and mechanical properties of the high temperature cure of vinyl ester resins. Journal of Applied Polymer Science, 92(2), 1124-1133. http://dx.doi.org/10.1002/ app.13686.

23. Chauhan, S. R., Kumar, A., \& Singh, I. (2010). Sliding friction and wear behaviour of vinylester and its composites under dry and water lubricated sliding conditions. Materials \& Design, 31(6), 2745-2751. http://dx.doi.org/10.1016/j. matdes.2010.01.020.

24. Suresha, B., Shiva Kumar, K., Seetharamu, S., \& Sampath Kumaran, P. (2010). Friction and dry slidinin wear behavior of carbon and glass fabric reinforced vinyl ester composites. Tribology International, 43(3), 602-609. http://dx.doi. org/10.1016/j.triboint.2009.09.009.

25. Correa, C. E., Betancourt, S., Vázquez, A., \& Gañan, P. (2017). Wear performance of vinyl ester reinforced with Musaceae fiber bundles sliging against differente metallic surfaces. Tribology 
International, 109(1), 447-459. http://dx.doi.org/10.1016/j. triboint.2017.01.009.

26. Manickam, C., Hariharan, K., Athijayamani, A. Experimental investigación of tribological behavior of hybrid and particulate reinforced vinyl ester composite. International Journal of Applied Engineering Research, 10(13), 11001-11004.

27. Rodriguez, E., Larrañaga, M., Mondragón, I., \& Vázquez, A. (2006). Relationship between the network morphology and properties of commercial vinyl ester resins. Journal of Applied Polymer Science, 100(5), 3895-3903. http://dx.doi. org/10.1002/app.22732.

28. Pritchard, G. (1998). Plastics additives. Netherlands: Springer.

29. Cvetanovska, A., \& Compston, P. (2004). Degree of cure and tensile properties of vinylester resin cured with ultraviolet light. Journal of Materials Science, 39(5), 1791-1793. http:// dx.doi.org/10.1023/B:JMSC.0000016186.59458.a1.

30. Xiancong, H., Meiwu, S., Guotai, Z., Hong, Z., Xiaopeng, H., \& Chunlan, Z. (2008). Investigation on the electron-beam curing of vinylester resin. Radiation Physics and Chemistry, 77(5), 643-655. http://dx.doi.org/10.1016/j.radphyschem.2007.11.006.

31. Dirand, X., Hilaire, B., Lafontaine, E., Mortaigne, B., \& Nardin, M. (1994). Crosslinking of vinyl ester matrix in contact with different surfaces. Composites, 25(7), 645-652. http://dx.doi. org/10.1016/0010-4361(94)90197-X.

32. Yang, H., \& Lee, L. J. (2001). A kinetic model for free-radical crosslinking co-polymerization of styrene/vinylester resin. Polymer Composites, 22(5), 668-679. http://dx.doi.org/10.1002/ pc. 10569 .

33. Scott, T. F., Cook, W. D., \& Forsythe, J. S. (2002). Photo-DSC cure kinetics of vinyl ester resins. I. Influence of temperature. Polymer, 43(22), 5839-5845. http://dx.doi.org/10.1016/S00323861(02)00490-1.

34. Zaske, O. C., \& Goodman, S. H. (1998). Unsaturated polyester and vinyl ester resins. In S. H. Goodman (Eds.), Handbook of thermoset plastics (2nd ed., pp. 97-162). Westwood: Noyes Publications.

35. Correa, C. E., Betancourt, S., Vázquez, A., \& Gañan, P. (2015). Wear resistance and friction behavior of thermoset matrix reinforced with Musaceae fiber bundles. Tribology International, 87(1), 57-64. http://dx.doi.org/10.1016/j.triboint.2015.02.015.

36. Sultania, M., Yadaw, S. B., Rai, J. S. P., \& Srivastava, D. (2010). Laminates based on vinyl ester resin and glass fabric: A study on the thermal, mechanical and morphological characteristics.
Materials Science and Engineering A, 527(18-19), 4560-4570. http://dx.doi.org/10.1016/j.msea.2010.04.038.

37. Auad, M. L., Aranguren, M., \& Borrajo, J. (1997). Epoxybased divinyl ester resin/styrene copolymers: Composition dependence of the mechanical and thermal properties. Journal of Applied Polymer Science, 66(6), 1059-1066. http://dx.doi. org/10.1002/(SICI)1097-4628(19971107)66:6<1059::AIDAPP6>3.0.CO;2-H.

38. Masson, J. F., Pelletier, L., \& Collins, P. (2001). Rapid FTIR method for quantification of styrene-butadiene type copolymers in bitumen. Journal of Applied Polymer Science, 79(6), 1034-1041. http://dx.doi.org/10.1002/1097-4628(20010207)79:6<1034::AIDAPP60>3.0.CO;2-4.

39. Kuo, P. Y., Yan, N., \& Sain, M. (2013). Influence of cellulose nanofibers on the curing behavior of epoxy/amine systems. European Polymer Journal, 49(12), 3778-3787. http://dx.doi. org/10.1016/j.eurpolymj.2013.08.022.

40. Pistor, V., Soares, S. S. D. S. D. S., Ornaghi, H. L., Jr., Fiorio, R., \& Zattera, A. J. (2012). Influence of glass and sisal fibers on the cure kinetics of unsaturated polyester resin. Materials Research, 15(4), 650-656. http://dx.doi.org/10.1590/S151614392012005000064 .

41. Omrani, A., Simon, L. C., \& Rostami, A. A. (2009). The effects of alumina nanoparticle on the properties of an epoxy resin sysem. Materials Chemistry and Physics, 114(1), 145-150. http://dx.doi.org/10.1016/j.matchemphys.2008.08.090.

42. Ehsani, M., Khonakdar, H. A., \& Ghadami, A. (2013). Assesment of morphological, thermal, and viscoelastic properties of epoxy vinyl ester coating composites. Role of glass flake and mixing method. Progress in Organic Coatings, 76(1), 238-243. http:// dx.doi.org/10.1016/j.porgcoat.2012.09.010.

43. Dua, S., Mccullough, R. L., \& Palmese, G. R. (1999). Copolymerization kinetics of styrene/vinyl-ester systems: Low temperature reactions. Polymer Composites, 20(3), 379-391. http://dx.doi.org/10.1002/pc.10364.

44. Kandelbauer, A., Tondi, G., Zaske, O., \& Goodman, S. H. (2014). Unsaturated polyesters and vinyl esters. In S. H. Goodman, \& H. Dodiuk-Kenig (Eds.), Handbook of thermoset plastics (3rd ed., pp. 111-172). San Diego: Elsevier.

Received: Dec. 21, 2016

Revised: Mar. 05, 2017

Accepted: Mar. 21, 2017 